\title{
ANÁLISE CLADISTICA DOS GÊNEROS DE MEMBRACINAE (HEMIPTERA, AUCHENORRHYNCHA, MEMBRACIDAE) ${ }^{1}$
}

\author{
Antonio José Creão-Duarte ${ }^{2}$ \\ Albino M. Sakakibara ${ }^{3}$
}

\begin{abstract}
Cladistic analysis of the Membracinae genera (Hemiptera, AuCHENORRHYNCHA, MEMBRACIDAE). Phylogeny for 23 Membracinae genera based on cladistic methodology is proposed. Five Hypsoprorini, two Aconophorini and sixteen Membracini genera were studied. The Hoplophorionini genera were also analysed. KEY WORDS. Hemiptera, Auchenorrhyncha, Membracidae, Cladistic analysis
\end{abstract}

DIETRICH \& MCKAMEY (1995) investigaram as relações filogenéticas dos gêneros de Membracinae e entre os resultados obtidos destacam: Trinarea Goding, 1929, como grupo-irmão de Hoplophorionini, Havilandia Dietrich \& McKamey, 1995, como grupo-irmão de Aconophorini e, em conseqüência Membracini como táxon parafilético. Essas conclusões divergiam de alguns resultados preliminares que foram observados quando do trabalho de revisão dos gêneros de Hoplophorionini. Fundamentalmente, essas divergências são decorrentes da interpretação diferente que foi dada a alguns caracteres e pela inclusão de outros, até então não abordados e que, conjuntamente, foram determinantes na obtenção de uma nova topologia. As tíbias clavadas, observadas em Trinarea e Hoplophorionini, que foram consideradas como um caráter sinapomórfico para esses táxons, são aqui entendidas como estruturas não homólogas. O tamanho subigual dos tarsos que ancorou a hipótese de que Havilandia e Aconophorini eram grupos-irmãos, pode decorrer de eventos históricos diferentes mas com resultados finais semelhantes e assim sendo tem um poder de decisão pequeno, não podendo apenas neste caráter se sustentar uma hipótese de ancestralidade comum. Assim, rejeitam-se neste trabalho as hipóteses de relação de parentesco anteriormente estabelecidas para Trinarea e Havilandia devido à reinterpretação dos caracteres que foram determinantes no estabelecimento daquelas hipóteses e pela inclusão de outros, anteriormente não abordados, e que conjuntamente apontam para uma hipótese de ancestralidade comum para os gêneros de Membracinae, aqui proposto como táxon monofilético.

1) Contribuição número 1040 do Departamento de Zoologia, Universidade Federal do Paraná.

2) Departamento de Sistemática e Ecologia, Universidade Federal da Paraíba. 58059-900 João Pessoa, Paraíba, Brasil.

E-mail:creao@dse.ufpb.br

3) Departamento de Zoologia, Universidade Federal do Paraná. Caixa Postal 19020, 81531-990 Curitiba, Paraná, Brasil. Bolsista do CNPq. 


\section{MATERIAL E MÉTODOS}

Foram examinadas espécies de 32 dos 38 gêneros incluídos em Membracinae. Os gêneros não analisados foram: Aconophora Fairmaire, 1846 (Aconophorini), Bolbonotodes Fowler, 1894 e Paragara Goding, 1926 (Membracini), Ramosella McKamey \& Deitz, 1996, Stirpis McKamey \& Deitz, 1996 e Turrialbia McKamey \& Deitz, 1996 (Hoplophorionini). Os gêneros dessa última tribo foram estudados apenas com o objetivo de levantar caracteres sinapomórficos que ancorassem o monofiletismo desse táxon.

A generalização dos caracteres, feita para cada um dos gêneros examinados, foi baseada, sempre que possível, em exemplares da espécie-tipo do gênero. As espécies estudadas foram: Hypsoprorini: Sphongophorus gracilis Sakakibara, 1977; Sphongophorus guimaraesi Sakakibara, 1981; Hypsoprorachis tuberosa Fonseca, 1969; Notocera brachycera (Fairmaire, 1846); Phylia inflata Metcalf, 1953; Hypsoprora albopleura Fonseca, 1933; Aconophorini: Guayaquila roreriana Goding, 1920; Calloconophora obtusa (Walker, 1851). Membracini: Bolbonota melaena (Germar, 1835); Campylenchia sp.; Enchenopa gracilis (Germar, 1818); Enchophyllum cruentatum (Germar, 1835); E. quinquemaculatum (Fairmaire, 1846); Erechtia bicolor Walker, 1858; Erechtia sp.; Eunusa concolor Fonseca, 1974; Folicarina bicolor Sakakibara, 1992; Havilandia pruinosa (Haviland, 1925), Kronides incumbens (Germar, 1835); Leioscyta spiralis Haviland, 1925; Lewdeitzia lunnata Dietrich \& McKamey, 1995; Membracis foliata (Linnaeus, 1758); M. celsa Walker, 1851; Phyllotropis fasciata (Fabricius, 1787); Trinarea appendiculata (Fonseca, 1936); Tritropidia nimbata (Fabricius, 1803); Tylopelta americana (Goding, 1893); Hoplophorionini: Alchisme inermis (Fairmaire, 1846); A. apicalis (Walker, 1851); A. turrita (Germar, 1835); A. mackameyi Creão-Duarte \& Sakakibara, 1997; Metcalfiella pertusa (Germar, 1835); M. semitecta (Walker, 1858); Ochropepla corrosa (Fairmaire, 1846); Platycotis tuberculata (Fairmaire, 1846); P. vitatta (Fabricius 1803); Potnia venosa (Germar, 1821), P. pinheiroi Creão-Duarte \& Sakakibara, 1996; Potnioides corniculatus Creão-Duarte, 1997; Sakakibarella elongata Creão-Duarte, 1997; S. seminigra Creão-Duarte, 1997; Stalotypa fairmairei (Guèrin, 1856); Umbonia richteri Creão-Duarte \& Sakakibara, 1996; U. spinosa (Fabricius, 1775).

A condição plesiomórfica dos estados de caracteres observados em Membracinae foi inferida por comparação no seu plano-básico, que vem a ser uma estratégia de reconstituição hipotética da espécie ancestral. O plano básico, além de reunir o conjunto das sinapomorfias do táxon, fornece ainda a condição plesiomórfica de todas as novidades evolutivas surgidas dentro desse táxon.

A reconstituição do plano-básico obedeceu o método de comparação com grupos externos (WATROUS \& WHEELER 1981) ou seja, os caracteres que variavam dentro de Membracini tiveram seus estados investigados em grupos externos, de onde se inferiu a condição plesiomórfica.

Para definição do grupo externo posicionou-se Membracinae como táxon terminal e, a partir disso, delimitou-se um agrupamento monofilético mais abrangente no qual Membracinae estivesse incluída. Este agrupamento, sem denominação 
formal, além de Membracinae, reúne Darninae, Heteronotinae e Smiliinae. Quinze espécies de gêneros diferentes, acomodados em onze tribos distintas, foram examinadas. São elas: Darninae: Darnini: Darnis lateralis (Fabricius, 1801) e Stictopelta acutula (Fairmaire, 1846). Cymbomorphini: Cymbomorpha vaginata (Germar, 1835); Hemikypthini: Hemikyptha punctata (Fabricius, 1775). Hyphinoini: Eualthe longa (Walker, 1851). Heteronotinae: Heteronitini: Heteronotus reticulatus (Burmeister, 1833), Omolon seabrai (Sakakibara, 1968), Smiliorachis octilinea Stål, 1869). Smiliinae: Acutalini: Acutalis tartarea (Say, 1830). Ceresini: Ceresa ustulata Fairmaire, 1946. Amastrini: Amastris sp. Smiliini: Thelia bimaculata (Fabricius, 1794), Cyrtolobus vau (Say, 1831). Tragopini: Tragopa albimaculata (Germar, 1821). Polyglyptini: Entylia gemmata (Germar, 1818).

A matriz de dados (Tab. I) foi submetida ao programa Hennig 86, versão 1.5 (FARRIS 1988). Sob o comando ie*; seis cladogramas foram gerados (número de passos evolutivos 59 ic 71 ir 85). Submetido esses cladogramas ao comando xs w; (pesos sucessivos, Tab. II) dois outros foram obtidos (número de passos evolutivos 351 ic 91 ir 96). O cladograma de consenso resultou da aplicação do comando ne; sobre esses dois últimos cladogramas.

Tabela I. Matriz de dados para análise cladística dos gêneros de Membracinae. Caracteres binários: (0) plesiomórfico, (1) apomórfico. Caracteres multiestado: a seqüência dos números, indica a série de transformação. Caracteres não comparados, são indicados por (?).

\begin{tabular}{lrrrrrrrr}
\hline \multirow{1}{*}{\multicolumn{1}{c}{ Táxons }} & \multicolumn{7}{c}{ Caracteres } \\
\cline { 2 - 8 } & & 1 & & 2 & 3 & & \\
& 12345 & 67890 & 12345 & 67890 & 12345 & 67890 & 12345 & 67 \\
\hline Grupo externo & 00000 & 00000 & 00000 & 00000 & 00000 & 00000 & 00000 & 00 \\
Hypsoprora & 11100 & 01000 & 11101 & 00000 & 12101 & $0000 ?$ & 01101 & 01 \\
Phylia & 11100 & 01000 & 10001 & 00000 & 12101 & $0000 ?$ & 01101 & 11 \\
Notocera & 11100 & 01000 & 01101 & 01100 & 12101 & $0000 ?$ & 01101 & 11 \\
Hypsoprorachis & 11100 & 00000 & 01101 & 00100 & 12101 & $0000 ?$ & $0110 ?$ & $0 ?$ \\
Sphongophorus & 10000 & 01000 & 00001 & 00000 & 12101 & $0000 ?$ & 01100 & 00 \\
Membracis & 21102 & 11000 & 00000 & 00000 & 12101 & 00100 & 10010 & 00 \\
Enchophyllum & 21102 & 11000 & 00000 & 00000 & 12101 & 00100 & 10010 & 00 \\
Phyllotropis & 21102 & 11000 & 00000 & 00000 & 12101 & 00100 & 10010 & 00 \\
Folicarina & 21102 & 11000 & 00000 & 00000 & 12101 & 00100 & 10010 & 00 \\
Tritropidia & 21102 & 01000 & 00000 & 00000 & 12101 & 00100 & 10000 & 00 \\
Enchenopa & 21102 & 01000 & 00000 & 00000 & 12101 & 00100 & 10010 & 00 \\
Campylenchia & 21102 & 01000 & 00000 & 00000 & 12101 & 00100 & 10010 & 00 \\
Kronides & 21102 & 01000 & 00000 & 00000 & 12101 & 00100 & 10010 & 00 \\
Havilandia & 21112 & 01000 & 00000 & 00000 & 12101 & 00110 & 00010 & 00 \\
Leioscyta & 21102 & 01000 & 00000 & 00000 & 12101 & 00110 & 00000 & 00 \\
Lewdeitzia & 21102 & 01000 & 00000 & 00000 & 12101 & 00110 & 00000 & 00 \\
Eunusa & 21110 & 00000 & 00000 & 00000 & 12101 & 10101 & 00000 & 00 \\
Bolbonota & 21102 & 01101 & 00010 & 00010 & 12101 & 10101 & 00000 & 00 \\
Tylopelta & 21102 & $0110 ?$ & 00010 & 00010 & 12201 & 10101 & 00000 & 00 \\
Erechtia & 21102 & 01112 & 00000 & 00000 & 02211 & 11101 & 00000 & 00 \\
Trinarea & 21102 & 01112 & 00000 & 00000 & 00201 & 11101 & 00000 & 00 \\
Calloconophora & 21101 & 00000 & 00000 & 00000 & 10201 & $0000 ?$ & 00000 & 00 \\
Guayaquila & 21101 & 00000 & 00000 & 00000 & 10201 & $0000 ?$ & 00000 & 00 \\
Hoplophorionini & 00000 & 00000 & 00000 & 11011 & 02011 & $0000 ?$ & 00000 & 00 \\
\hline & & & & & & & & \\
\hline
\end{tabular}


Tabela II. Pesos atribuidos aos caractereres pelo comando xs w; do programa Hennig86, versăo 1.5 .

\begin{tabular}{cccccc}
\hline Caracteres & Pesos & Caracteres & Pesos & Caracteres & Pesos \\
\hline 01 & 10 & 14 & 10 & 27 & 10 \\
02 & 01 & 15 & 10 & 28 & 10 \\
03 & 02 & 16 & 10 & 29 & 10 \\
04 & 00 & 17 & 00 & 30 & 10 \\
05 & 04 & 18 & 10 & 31 & 10 \\
06 & 10 & 19 & 10 & 32 & 10 \\
07 & 01 & 20 & 10 & 33 & 10 \\
08 & 10 & 21 & 02 & 34 & 04 \\
09 & 10 & 22 & 02 & 35 & 10 \\
10 & 10 & 23 & 10 & 36 & 00 \\
11 & 00 & 24 & 02 & 37 & 10 \\
12 & 10 & 25 & 10 & & \\
13 & 10 & 26 & 10 & & \\
\hline
\end{tabular}

A análise de consenso empregada foi a de consenso estrito, a qual se caracteriza por aproveitar no cladograma final apenas os grupos monofiléticos que estão presentes em todos os cladogramas que portam o mesmo número de passos evolutivos.

\section{RESULTADOS E DISCUSSÕES}

\section{Plano-básico de Membracinae}

Tegumento não recoberto por cera em nenhuma fase do desenvolvimento. Cabeça, em vista frontal, triangular. Olhos semiglobulares. Ocelos eqüidistantes entre si e dos olhos, situados sobre a linha imaginária que passa pelo centro dos olhos. Pós-clípeo intumescido, não foliáceo, destituído de carena transclipeal e em plano diferente do anteclípeo. Placas maxilares triangulares, sobrepostas pelas mandibulares, não se projetando para a base das coxas I.

Pronoto não foliáceo, liso; margens laterais retas, sem curva pós-umeral. Processo anterior presente mas destituído de carenas. Ângulos umerais não se projetando além da base das asas. Carena mediana percurrente reta, bem definida, mas sem aspecto foliáceo. Processo posterior acuminado, linha dorsal reta e com as margens laterais tangenciando as margens internas das tégminas em toda sua extensão.

Sutura mesopleural bem definida em toda sua extensão. Mesepisterno liso.

Tíbias normais, não foliáceas. Tíbias III com as arestas I e II separadas em toda extensão do seu comprimento onde ocorrem setas cuculadas, em fileira simples desde a base até o ápice; aresta III com setas cuculadas no quarto apical e dispersas em grande número por toda a superfície interna.

Tarsos I e II bem desenvolvidos porém nunca alcançando a proporção de dois terços do comprimento das tíbias. Tarsos III bem desenvolvidos, maiores que os tarsos I e II. 
Tégminas com cinco células apicais e duas discoidais; pontuadas e ligeiramente coriáceas na metade proximal da margem anterior, entre as veias Costa e Média e na base do clavo, onde ocorre uma veia anal. Veia Sector bifurcada um pouco além do meio das tégminas, dando origem a Sector anterior e a posterior. Sector anterior bifurcando-se dando origem a S1, que deflete para a margem costal, e S2 que segue em direção ao ápice. Sector posterior indivisa representando a fusão dos ramos S3 e S4; paralela ao ramo S2, ao qual se une pela veia transversal s.

Veia Média fundida na base à veia Cúbito; bifurcando-se no terço apical dando origem aos ramos $\mathrm{M} 1+2$, que se liga ao $\mathrm{S} 3+4$ pela veia transversal s-m, e $\mathrm{M} 3+4$ que se liga a veia Cúbito pela veia transversal (m-cu)2. A veia transversal (m-cu) 1 , ocorre um pouco antes do meio.

Asas posteriores com quatro células apicais. Estrutura de acoplamento (frênulo) situada mais próxima do ápice que da base da asa. Veia Sector e veia Média bifurcando-se um pouco antes da estrutura de acoplamento. Veia Sector com os ramos $\mathrm{S} 1+2$ e $\mathrm{S} 3+4$. Veia Média com $\mathrm{M} 1+2$ ligado ao $\mathrm{S} 3+4$ pela veia transversal s-m e M3+4 ligado pela m-cu à veia Cúbito, indivisa. Duas veias anais fundidas na base. Lóbulo jugal bem desenvolvido, mais longo que largo, com o ápice livre e destacado.

Abdome fusiforme. O pigóforo das fềmeas, com as valvas alcançando o seu ápice. Nos machos o pigóforo com as placas laterais bem definidas, não carenadas. Placa subgenital estreita, não encobrindo a genitália.

\section{Caracteres utilizados}

1) Superfície do corpo. (0) Não recoberta por cera em nenhum estágio do desenvolvimento. (1) Recoberta por cera tanto na fase de ninfa quanto na de adulto. (2) Recoberta de cera apenas na fase de ninfa.

A interpretação do sentido da série de transformação segue a seguinte suposição: os insetos não recobertos por cera em nenhum estágio do seu ciclo de vida, são aqueles desprovidos de glândulas secretoras. Os insetos recobertos por cera tanto na fase de ninfa como na de adulto, são aqueles cujas glândulas secretoras de cera permanecem na fase adulta. Os insetos recobertos de cera apenas na fase de ninfa, são aquelas cujas glândulas foram suprimidas durante a passagem para a fase adulta.

A condição apomórfica intermediária é uma sinapomorfía para Hypsoprorini, Aconophorini e Membracini e a condição mais apomórfica, uma sinapomorfia para Aconophorini e Membracini.

2) Pós-clípeo, forma. (0) Não foliáceo. (1) Foliáceo (Fig. 1 a, b).

O pós-clípeo foliáceo é expandido lateralmente, sobrepondo, pelo menos em parte, as placas mandibulares e em geral encobrindo apicalmente a base do anteclípeo.

3) Pós-clípeo, carena transclipeal. (0) Ausente mas, se presente, então em forma de V e não completamente definida em toda sua extensão. (1) Presente, em forma de arco e bem definida em toda sua extensão (Fig. 1 a, b).

4) Pós-clípeo, posição. (0) Em plano diferente do anteclípeo. (1) No mesmo plano do anteclípeo (Fig. $1 \mathrm{c}$ ). 

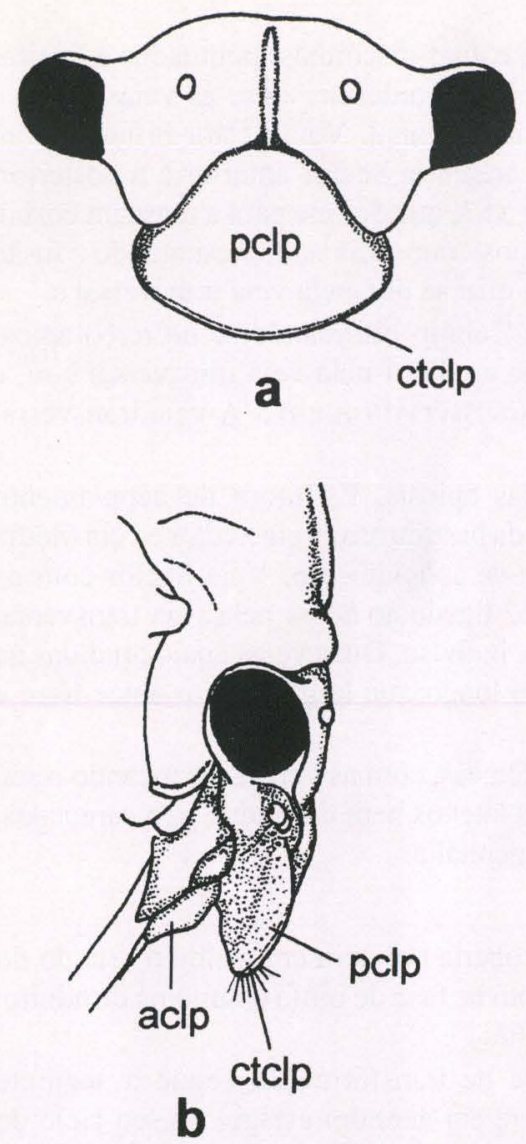

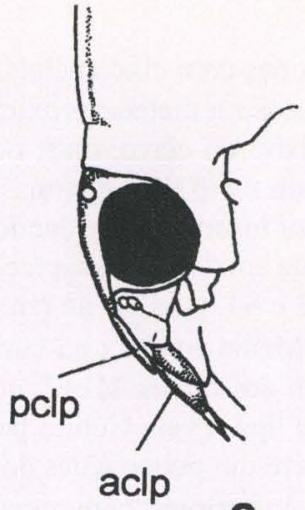

aclp

C

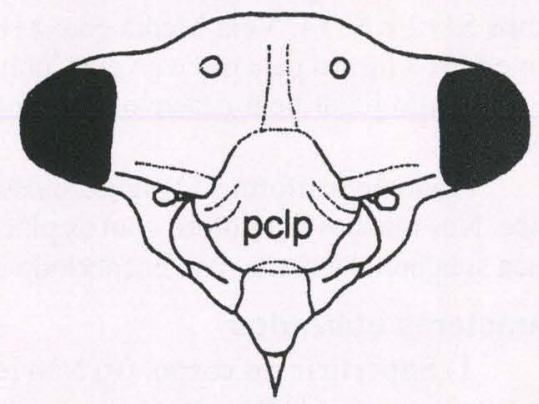

d

Fig. 1. (a, b) Erechtia sp.; (c) Havilandia pruinosa; (d) Potnia venosa. (aclp) Anteclípeo, (ctclp) carena transclipeal, (pclp) pós-clipeo.

5) Carena mediana percurrente, aspecto. (0) Não laminada. (1) Laminada na parte anterior (Fig. 2 b). (2) Laminada em toda sua extensão (Figs 2 a, c; 3 a, b; 4 a).

O caráter na condição apomórfica intermediária é uma sinapomorfia para Aconophorini + Membracini, com reversão em Eunusa e na condição mais apomórfica, uma sinapomorfia para Membracini. Em Kronides a carena não é laminada na região mediana. Essa perda da forma laminada na região mediana, foi aqui interpretada como um evento autapomórfico do gênero.

6) Forma do pronoto. (0) Não foliáceo. (1) Foliáceo (Fig. 2 a).

A condição apomórfica é uma sinapomorfia para Membracis, Phyllotropis, Enchophyllum e Folicarina (Membracini). $4 \mathrm{a}, \mathrm{b}, \mathrm{c})$.

7) Carena dorso-lateral. (0) Ausente. (1) Presente (Figs 2 a, c, d; 3 a, b, c;

8) Carenas supra-umerais. (0) Ausentes. (1) Presentes (Figs 2 c; 3 a,b). 

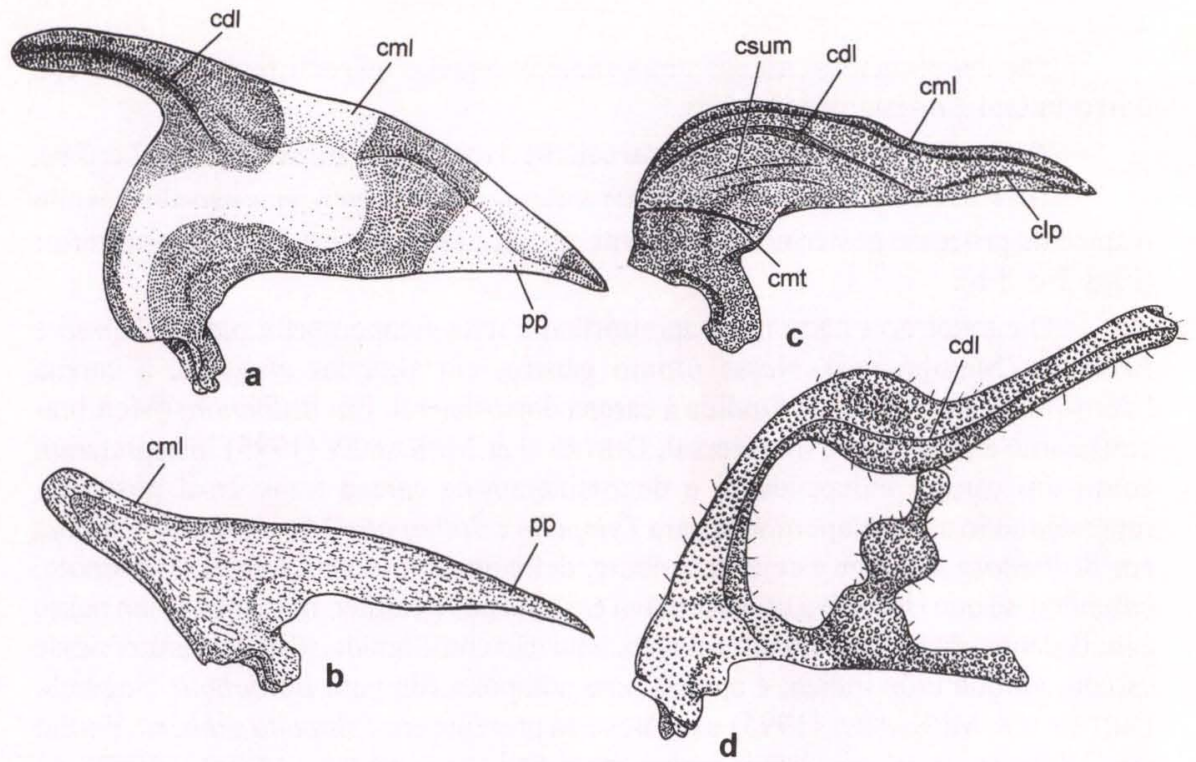

Fig. 2. (a) Enchophyllum cruentatum; (b) Guayaquila roreriana; (c) Erechtia sp.; (d) Sphongophorus gracilis. (cdl) Carena dorso-lateral, (clp) carena látero-posterior, (cml) carena mediana laminada, (cmt) carena metopidial transversal, (csum) carena supra-umeral, $(\mathrm{pp}$ ) processo posterior.
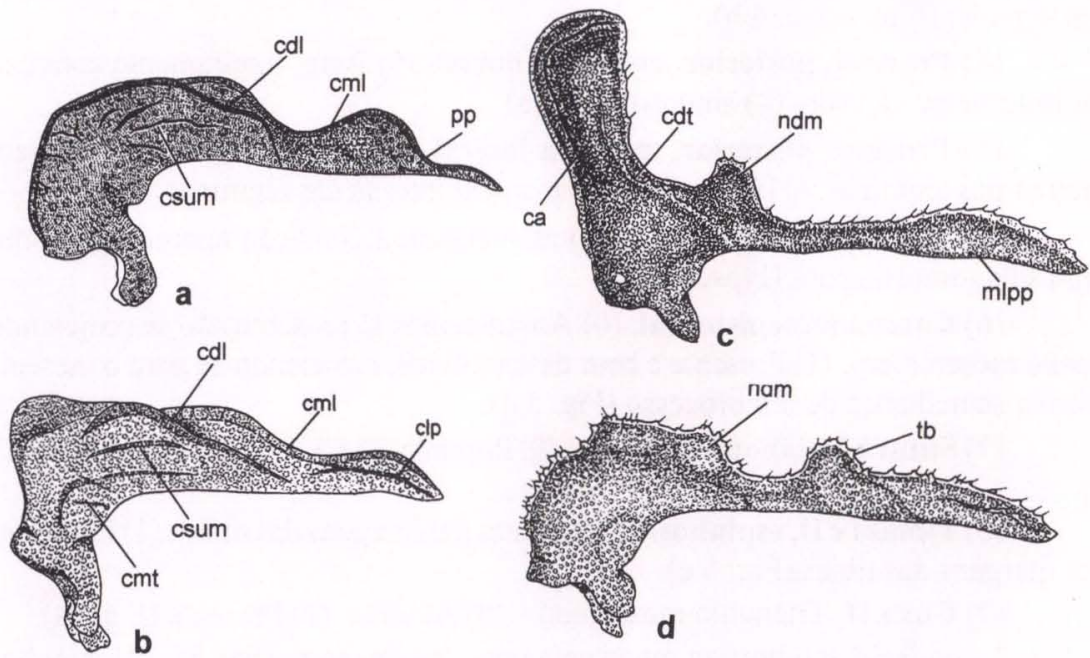

Fig. 3. (a) Tylopelta americana; (b) Trinarea appendiculata; (c) Hypsoprora albopleura; (d) Hypsoprorachis tuberosa. (ca) Carena mediana, (cdl) carena dorso-lateral, (clp) carena látero-posterior, $(\mathrm{cml})$ carena mediana laminada, $(\mathrm{cmt})$ carena metopidial transversal, (csum) carena supra-umeral, (mlpp) margem lateral do processo posterior, (ndm) nódulo dorsal mediano, (pp) processo posterior, (tb) tuberosidade pronotal. 
São denominadas carenas supra-umerais aquelas que ocorrem entre a carena dorso-lateral e os ângulos umerais.

9) Carena metopidial transversal. (0) Ausente. (1) Presente (Figs 2 c; 3 b).

10) Carena látero-posterior. (0) Ausente. (1) Presente, mas não alcançando o ápice do processo posterior. (2) Presente, alcançando o ápice do processo posterior (Figs $2 \mathrm{c} ; 3 \mathrm{~b}$ ).

O caráter no estado mais apomórfico é uma sinapomorfia para Trinarea e Erechtia (Membracini). Nesse último gênero, em algumas espécies, a carena látero-posterior pode estar fundida à carena dorso-lateral. Em Bolbonota (Membracini) como essa carena é transversal, DIETRICH \& MCKAMEY (1995) interpretaram como um caráter independente e denominaram-na carena transversal posterior, representando uma sinapomorfia para Tylopelta e Bolbonota (Membracini). Embora em Bolbonota a carena esteja, realmente, defletida da margem lateral do pronoto, entendeu-se que isso não a transformava em uma novo caráter, mas apenas um passo a mais dentro da série de transformação, aqui não considerada, já que o caráter nesse estado, ao que tudo indica, é apenas uma autapomorfia para Bolbonota. Segundo DiETRICH \& MCKAMEY (1995) o caráter está presente em Tylopelta gibbera. Porém em Tylopelta americana, espécie aqui examinada, essa carena é ausente. Assim, na matriz de caracteres, assinalou-se (?) para Tylopelta.

11) Carena anterior. (0) Ausente. (1) Presente (Figs $3 \mathrm{c} ; 4$ c).

12) Nódulo dorso mediano. (0) Ausente. (1) Presente (Figs 3 c, d; 4 b).

13) Tuberosidades pronotais. (0) Ausentes. (1) Presentes e encimadas por um espinho (Figs $3 \mathrm{c}$, d; 4 b).

14) Processo posterior, contorno dorsal. (0) Reto, ligeiramente convexo ou fortemente elevado. (1) sinuoso (Fig. 3a)

15) Processo posterior, margem lateral. (0) Não sobrepondo a margem interna das tégminas. (1) Sobrepondo a margem interna das tégminas.

DiETRICH \& MCKAMEY (1995) assinalaram a condição apomórfica como uma sinapomorfia para Hypsoprorini.

16) Carena mesepisternal. (0) Ausente, mas se presente não se projetando para o mesepimero. (1) Presente e bem desenvolvida, projetando-se para o mesepimero a semelhança de um processo (Fig. 5 d). b).

17) Sutura metanotal mediana. (0) Presente (Fig.5 a, c). (1) Ausente (Fig.5

18) Tíbias I e II, espinhos. (0) Ausentes nas margens das tíbias. (1) Presentes nas margens das tíbias (Fig. $6 \mathrm{c}$ ).

19) Coxa II. Triângulo mesocoxal - (0) Ausente. (1) Presente (Fig. 6a).

A condição apomorfica representa uma das sinapomorfias para Hoplophorionini. $\mathrm{O}$ fato de algumas espécies de Alchisme não apresentarem o triângulo mesocoxal foi aqui entendido como uma reversão que ocorreu secundariamente dentro do gênero.

20) Tíbias III, arestas I e II. (0) Separadas em toda extensão (Figs 6 c; 7 a, c). (1) Fundidas nos três quartos apicais (Figs 6 b; 7 d). 

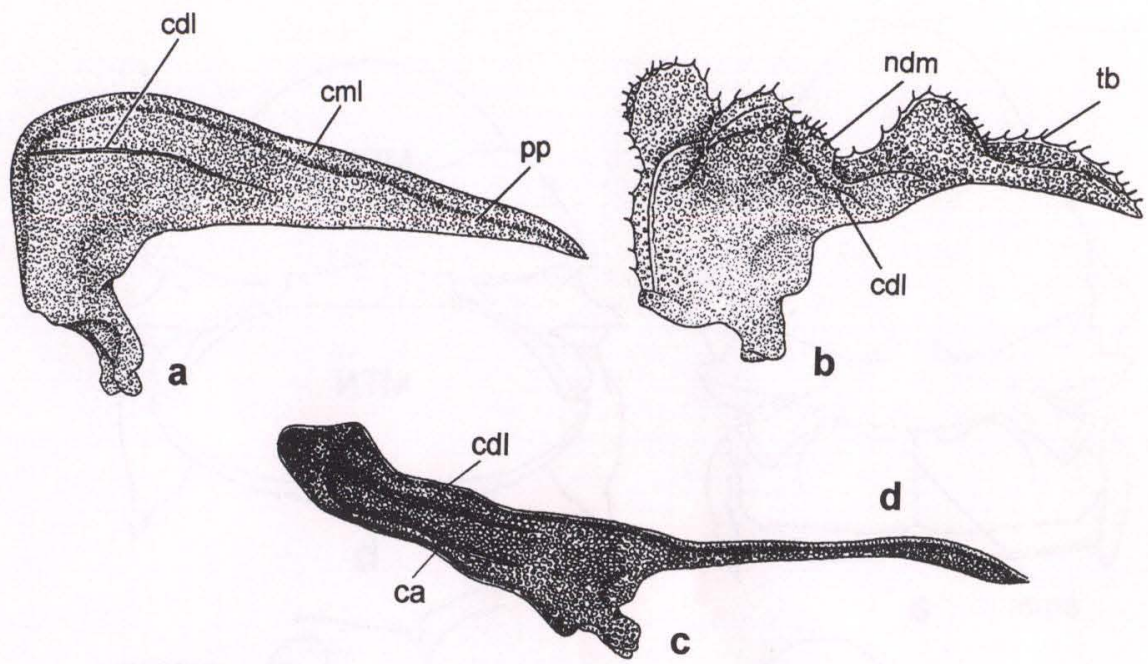

Fig. 4. (a) Leioscyta spiralis; (b) Notocera brachycera; (c) Phylia inflata. (ca) Carena anterior, (cdl) carena dorso-lateral, ( $\mathrm{cml}$ ) carena mediana laminada, $(\mathrm{ndm})$ nódulo dorsal mediano, $(\mathrm{pp})$ processo posterior, (tb) Tuberosidade pronotal.

DIETRICH \& MCKAMEY (1995) definiram como grupo irmão de Hoplophorionini, o gênero Trinarea (Membracini), tendo em vista o compartilhamento dos caracteres: tíbias III clavadas e tarsos III menores que os tarsos I e II. Sem dúvida, Hoplophorionini e Trinarea têm tíbias clavadas, porém examinando-as concluiu-se que foram eventos históricos diferentes que levaram as tíbias a apresentarem formas identificadas como clavadas. Em Hoplophorionini a superfície externa desapareceu devido a fusão da aresta I e II, conforme pode ser observado, principalmente, em Umbonia (Fig. 6 b). Outra evidência, que conduz ao mesmo raciocínio, é a aresta dupla de cerdas cuculadas que ocorre em Potnia (Hoplophorionini), indicando que se tratam de espinhos das arestas I e II. Em Trinarea essas arestas permanecem separadas e a superfície externa da tíbia está bem definida, sendo, inclusive, dilatada no ápice. Conclui-se que essas tíbias, embora denominadas clavadas, não são homólogas. $7 \mathrm{c})$.

21) Tíbias III, espinho adlateral à aresta II. (0) Ausente. (1) Presente (Fig.

22) Tíbias III, cerdas cuculadas da aresta III. (0) Tão proeminentes quanto as das arestas I e II. (1) Menos proeminentes que as das arestas I e II. (2) Sem cerdas cuculadas na aresta III.

DEITZ (1975) ao descrever os caracteres diagnósticos de Membracinae, mencionou que a aresta III das tíbias III ou era destituída de cerdas cuculadas ou essas cerdas, quando presentes, eram menos proeminentes, se comparadas com as que ocorriam nas arestas I e II.

DIETRICH \& DEITZ (1991) efetuaram a análise cladística de Aconophorini na qual 48 espécies foram usadas como táxons terminais. Nesse trabalho o caráter 24 trata da presença e da ausência de cerdas cuculadas na aresta III. Entre as espécies analisadas, 45 portavam cerdas cuculadas. 

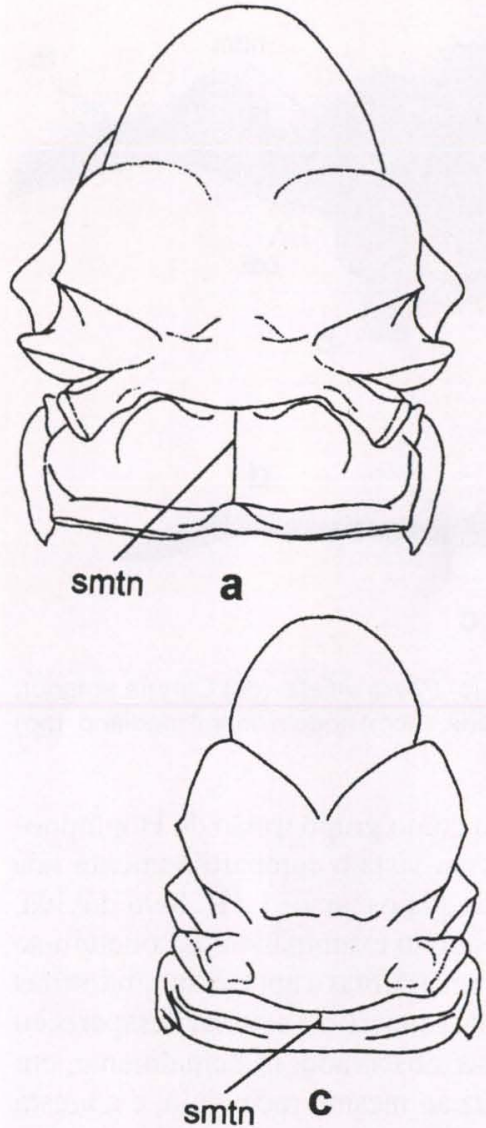

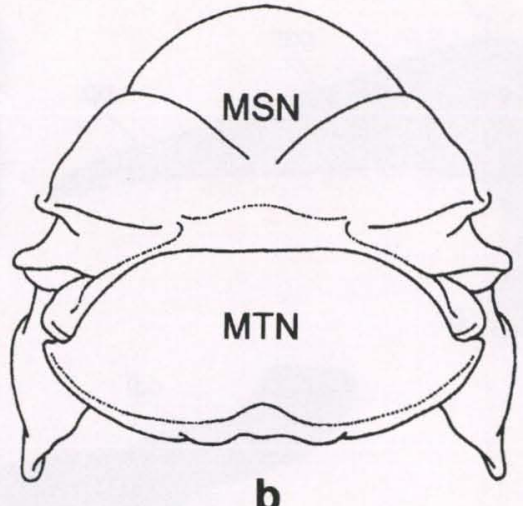

b

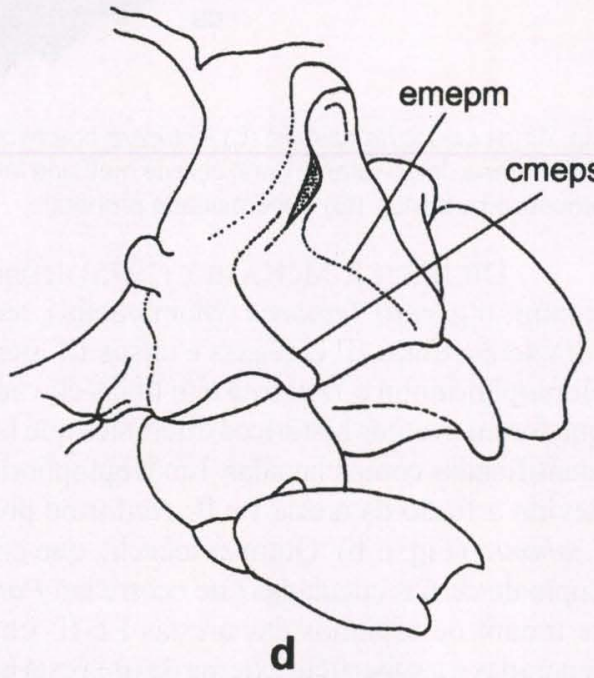

Fig. 5. (a) Kronides incumbens; (b) Potnia venosa; (c) Sphongophorus gracilis; (d) Metcalfiella pertusa (mesopleura). (emepm) Elevação mesepimeral, (cmeps) carena mesepisternal, (MSN) mesonoto, (MTN) metanoto, (smtn) sutura metanotal mediana.

O caráter apresenta três passos evolutivos. No estado mais apomórfico é uma sinapomorfia para Membracinae. No estado apomórfico intermediário é uma sinapomorfia para Aconophorini.

23) Tíbias III, tamanho das cerdas cuculadas das arestas I e II. (0) Com cuculos normais. (1) Com espinhos curtos (Fig. 6 c). (2) Com espinhos bem desenvolvidos (Fig. 7 c).

Segundo McKamey \& Deitz (1996), Potnia Stål é o gênero mais basal de Hoplophorionini. Nesse gênero as tíbias III têm cuculos normais. Assim, foi assinalada a condição plesiomórfica para a tribo. A ausência de cerdas cuculadas, que ocorre em outros gêneros dentro deste táxon, foram aqui entendidas como perdas secundárias. 


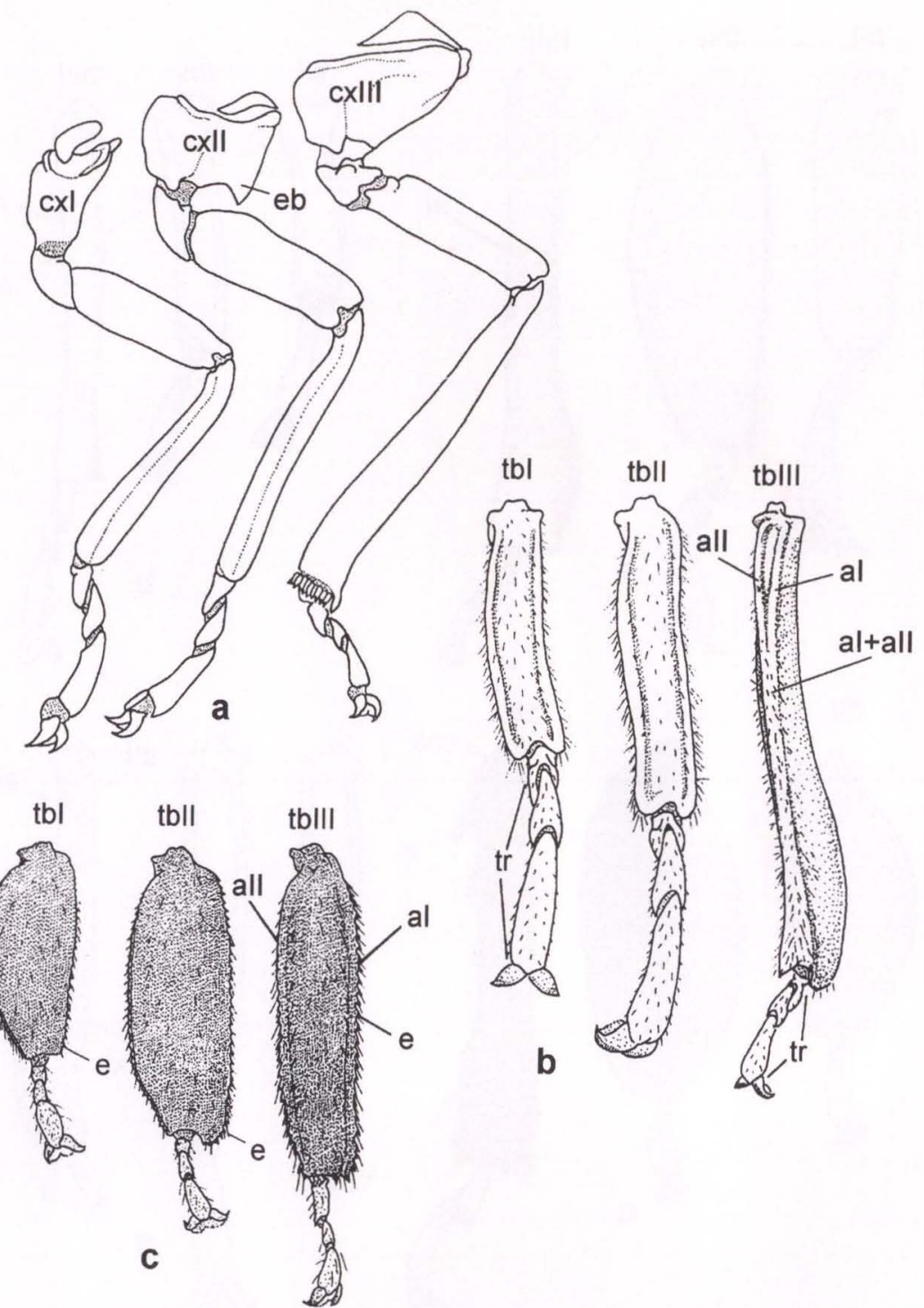

Fig. 6. (a) Alchisme inermis; (b) Umbonia spinosa; (c) Notocera brachycera. (a I, a II) Aresta um e dois, (a I+II) fusão das arestas I e II, (cx I, II, III) coxas pro-meso-metatorácicas, (e) espinho, (tb I, II, III) tíbias pro-meso-metatorácicas, (tm) triângulo mesocoxal, (tr) tarsos.

24) Tarsos III, tamanho em relação aos tarsos I e II. (0) Tão longos ou mais longos (Figs $6 \mathrm{c} ; 7$ b, c). (1) Menores (Figs $6 \mathrm{a}, \mathrm{b} ; 7 \mathrm{a}$, d).

25) Veia Subcosta em relação a margem anterior. (0) Contígua em toda sua extensão. (1) Contígua em sua metade basal, deixando em sua metade distal uma área membranosa. 

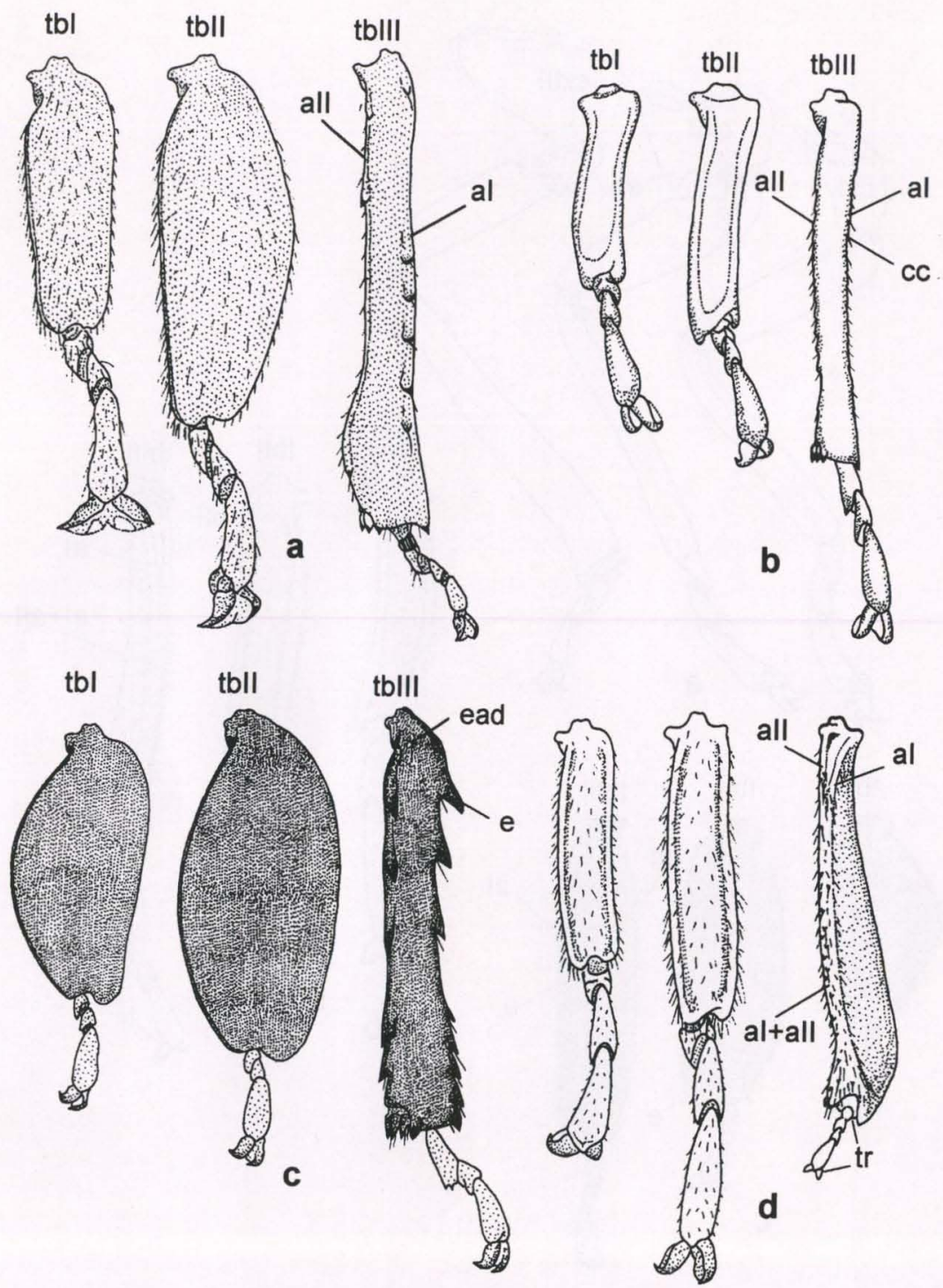

Fig. 7. (a) Trinarea appendiculata; (b) Stictopelta acutula; (c) Tylopelta americana; (d) Potnia venosa. (a I, a II) aresta um e dois, (a I+II) fusão das arestas I e II, (cc) cerdas cuculadas, (e)

- espinho, (tb I, II, III) tíbias pro-meso-metatorácicas, (tr) tarsos, (ead) espinho adlateral à aresta II.

FunKHOUSER (1913), estudando a homologia das veias das asas de Membracidae, observou que as asas anteriores das ninfas de Hoplophorida (Sic) e Membracida (Sic) tinham em comum a condição a cima definida como apomórfica, que representa uma sinapomorfia para Membracinae. 
26) Tégminas das fêmeas, margem costal. (0) Não inteiramente ajustada ao contorno lateral do corpo. (1) Inteiramente ajustada ao contorno lateral do corpo.

27) Tégminas, número de células discoidais. (0) Duas. (1) Três (Fig. 8 a).

Outra sinapomorfia para Trinarea e Erechtia (Membracini). Embora algumas espécies de Erechtia apresentem apenas duas discoidais, interpretou-se como pertencentes às quebras mais apicais, onde o caráter havia revertido à condição plesiomórfica.

28) Tégminas, sector anterior (Sa). (0) Sa dividida em $\mathrm{S}_{1}$ e $\mathrm{S}_{2}$ (Fig. 8 b). (1) Sa não dividida $\left(\mathrm{S}_{1+2}\right)$ (Fig. 8 a, c, d).

Heteronotinae, Smiliinae e Stegaspidinae exibem a condição plesiomórfica. Em Darninae, apenas Hebetica, Aspona e Hebeticoides apresentam um sistema de ramificação para a Sector que, aparentemente, se assemelharia ao que ocorre em Membracini, porém nesses gêneros a veia transversa s é ausente.

A interpretação dada por DEITZ (1975) ao sistema de venação dos ramos da veia RS, (ou veia S) para Centrotinae e Nessorhininae sugere, exceto pela presença de uma segunda transversa s-m, ser semelhante ao que ocorre em Membracini. Todavia, como Centrotinae e Nessorhininae são táxons mais basais, dentro de Membracidae, o sistema de ramificação da veia S em Membracini é aqui interpretado como um evento histórico independente.

29) Tégminas, ramos da veia sector. (0) Todos ou pelo menos S1 curvado para a margem costal. (1) Retos, dirigido para o ápice, não curvados para a margem (Fig. 8 d).

30) Tégminas (com o padrão $S_{1+2}, S_{3}$ e $S_{4}$ ), ramo $\mathbf{S 1}$. (0) Longo, pelo menos duas vezes mais que Sp. (1) Curto, não excedendo muito a Sp (Fig. 8 a).

31) Tégminas, textura. (0) Não uniforme. (1) Uniforme (Fig. 8 c).

A condição apomórfica é uma sinapomorfia para Tritropidia Enchenopa, Kronides, Membracis, Enchophyllum, Phyllotropis e Folicarina (Membracini).

32) Asas posteriores, frênulo. (0) Situado depois do meio da asa. (1) Situado ao meio ou um pouco antes (Fig. 8 b).

O caráter no estado derivado é sinapomórfico para Hypsoprorini.

33) Asas posteriores, limbo. (0) Não sinuoso na margem anterior. Sinuoso na margem anterior (Fig. 8 b).

A condição apomórfica é uma sinapomorfia para Hypsoprorini.

34) Asas posteriores, ápice do lóbulo jugal. (0) Destacado. (1) Não destacado (Fig. 8 c).

35) Machos, margem da placa lateral do pigóforo. (0) Lisa. (1) Serrilhada (Fig. 9 b, c, d).

36) Machos, ápice da placa subgenital. (0) Não dilatado (Fig. 9 a). (1) Dilatado (Fig. 9 b, d).

37) Machos, placa lateral do pigóforo. (0) Curta. (1) Longa, quase alcançando o ápice do pigóforo (Fig. 9 b, c, d).

A condição apomórfica é mais uma sinapomorfia para Phylia, Notocera e Hypsoprora (Hypsoprorini). Na matriz de dados foi plotada uma interrogação em Hypsoprorachis, pois não se dispunha de exemplares machos, mas espera-se que o caráter ocorra nesse gênero, na condição apomórfica. 

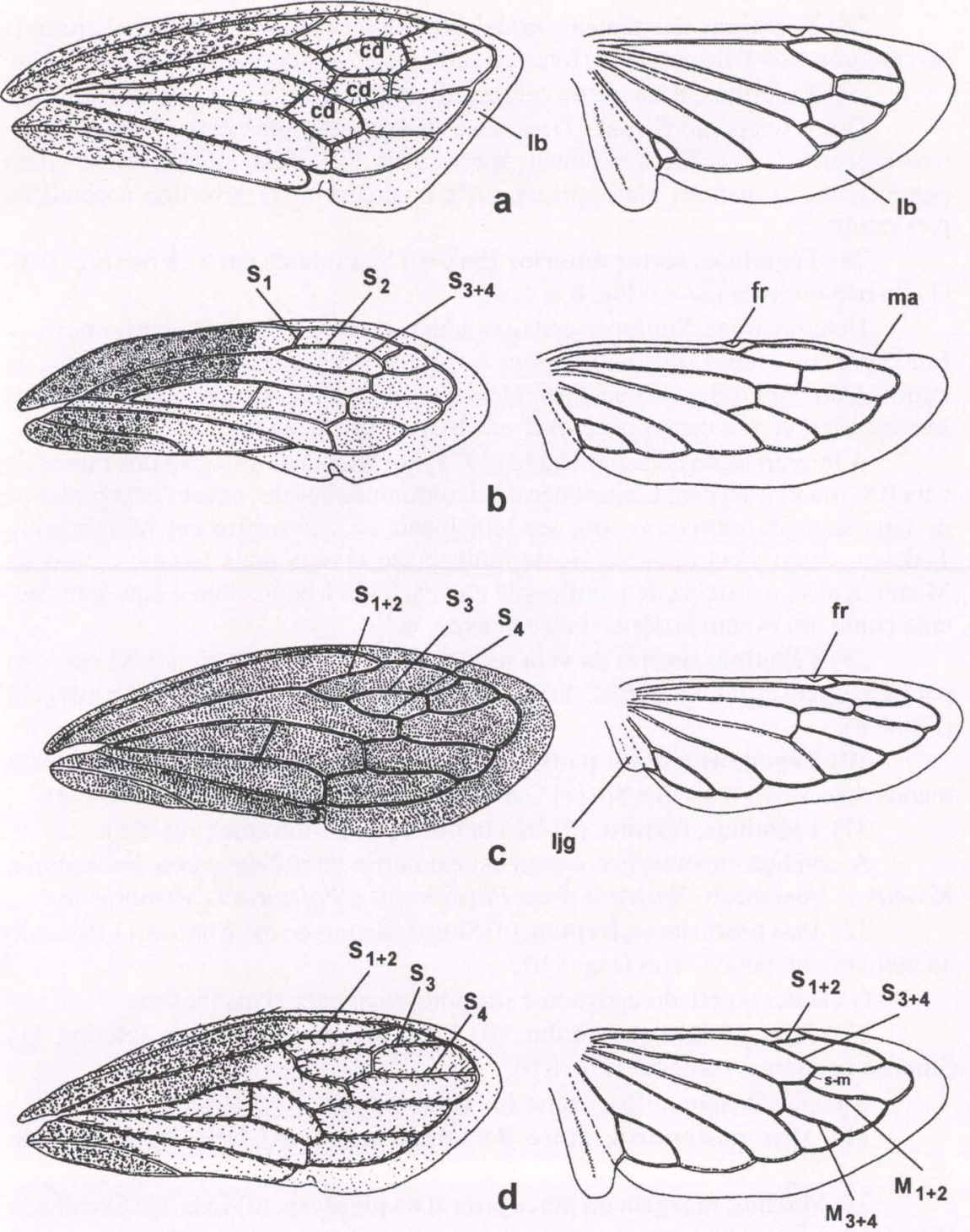

Fig. 8. (a) Trinarea appendiculata; (b) Hypsoprora albopleura; (c) Membracis foliata; (d) Leioscyta spiralis. (cd) Célula discal, (fr) frênulo, (lb) limbo, (ljg) lóbulo jugal, (ma) margem anterior, $\left(M_{1+2}, M_{3+4}\right)$ ramos da veia média, $(S 1, S 2, S 3+4)$ ramos da veia sector.

\section{Cladograma de consenso: análise e comentários}

Para se discutir as hipóteses de relações de parentesco, parte-se do princípio que a história dessas relações é desconhecida e que toda informação resume-se em uma politomia, na qual os táxons são reunidos (Fig. 11 a). Os caracteres de maior 
generalidade, supostamente, mais confiáveis são, então, plotados à politomia buscando o esclarecimento das relações entre os táxons. O caráter 22(2) e o 25(1) apresentam esta condição e são os definidores do monofiletismo de Membracinae.
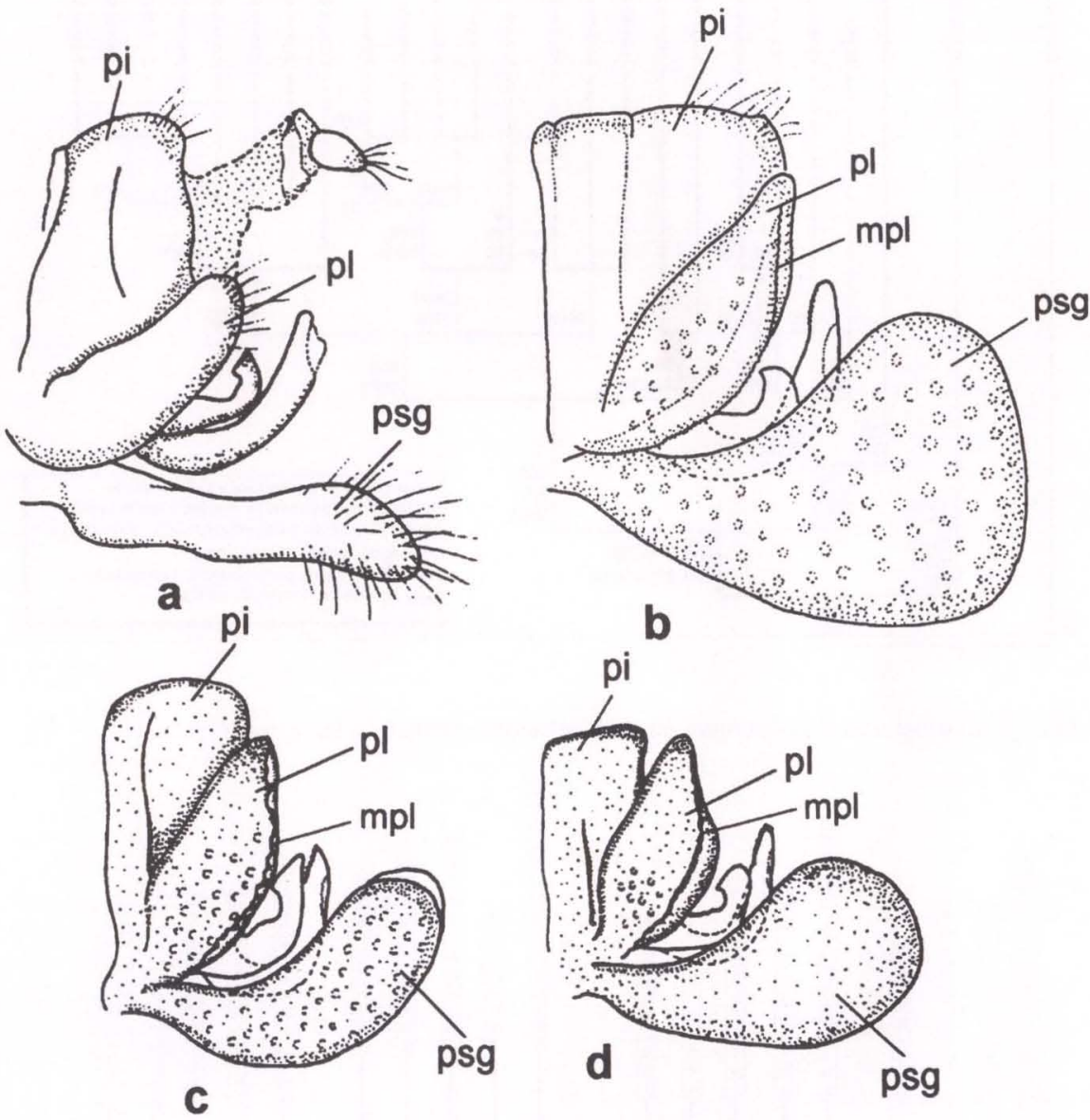

Fig. 9. (a) Enchophyllum cruentatum; (b) Notocera brachycera; (c) Phylia inflata; (d) Hypsoprora albopleura. (mpl) Margem da placa lateral do pigóforo, (pi) pigóforo, ( $\mathrm{pl}$ ) placa lateral, (psg) placa subgenital.

Os caracteres 1(1), 2(1), 3(1), 7(1), 21(1) e 24(1) são, agora, os de maior nível de generalidade e reúnem as tribos Hypsoprorini, Aconophorini e Membracini em um táxon monofilético, que tem por grupo-irmão Hoplophorionini.

O monofiletismo de Hoplophorionini é altamente confiável, estando ancorado por cinco sinapomorfias: Tíbias III com arestas I e II fundidas nos três quartos apicais; carena mesepisternal bem desenvolvida projetando-se sobre o mesepisterno; triângulo mesocoxal (com reversão em algumas espécies de Alchisme), sutura 


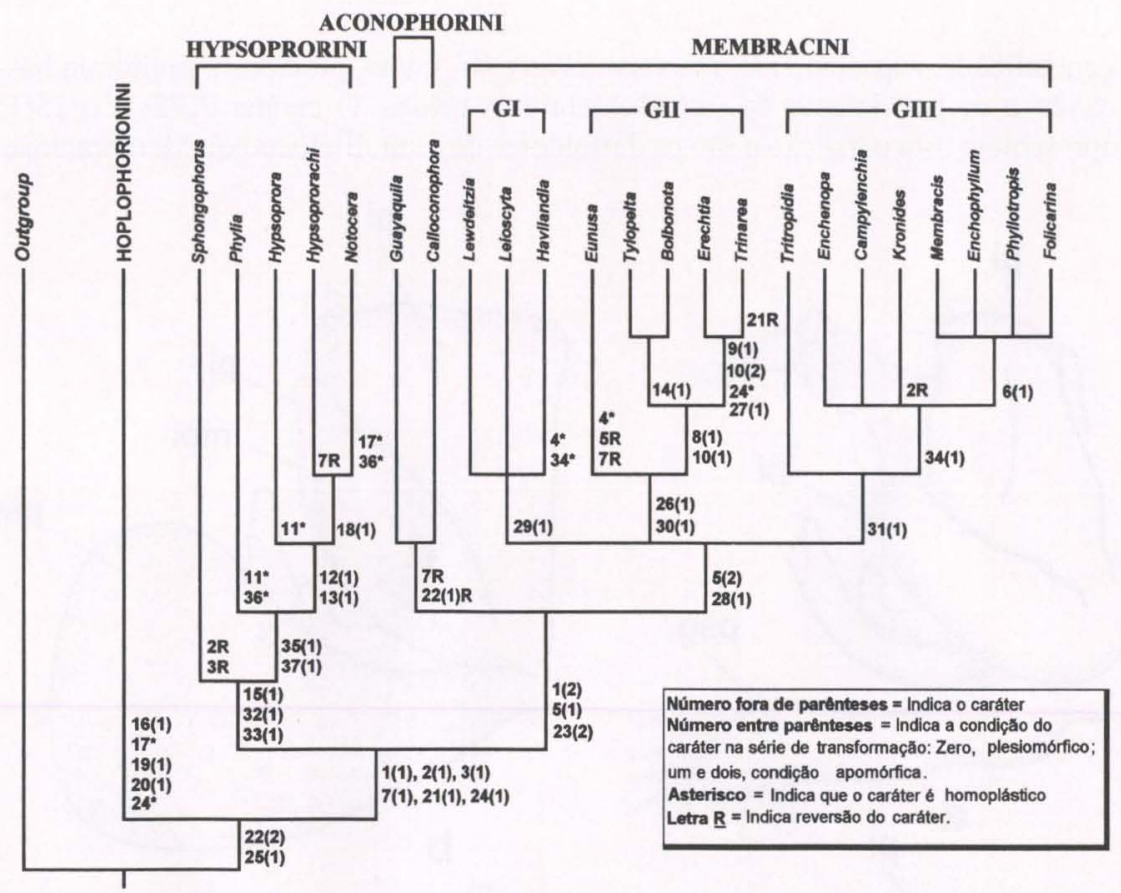

Fig. 10. Cladograma de consenso gerado pelos comandos $i e^{*} ;$ xs w; e ne;
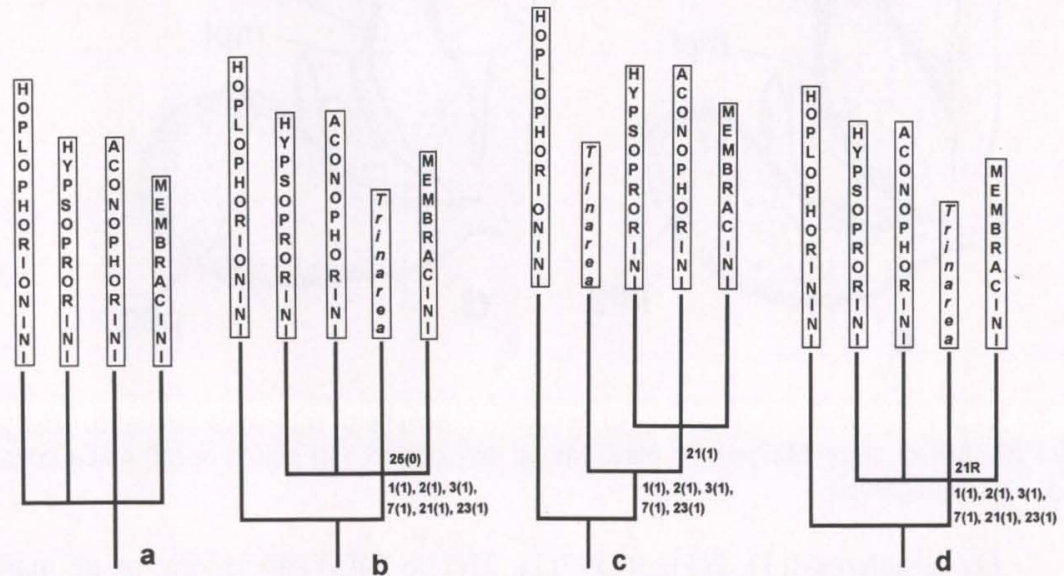

Fig. 11. (a) Politomia inicial para as tribos de Membracinae; (b-d) conflito na distribuição do caráter 21.

notal-mediana ausente no metanoto (em Hypsoprora esta sutura também está ausente) e tarsos III reduzidos (ocorrendo também em Erechtia e Trinarea). Hoplophorionini é grupo irmão de Hypsoprorini + Aconophorini + Membracini. 
Os caracteres 1(1), 2(1), 3(1), 7(1), 21(1) e 23(1) são apresentados como sinapomórficos para Hypsoprorini, Aconophorini e Membracini (Fig. 11 b). Os caracteres 1(1) e 23(1) não apresentam conflitos com outros estados de caracteres e são inteiramente congruentes com todas as demais hipóteses. O caráter $21(0)$ ocorre em Trinarea. A ausência da condição apomórfica do caráter 21 poderia sugerir uma posição mais basal para este gênero, que estaria, desta maneira, separado de Hypsoprorini, Aconophorini e Membracini, visto que essas tribos portam o caráter 21 no estado apomórfico, o qual, assim, pode ser interpretado como menos abrangente (Fig. 11 c). Esta hipótese, pela análise dos caracteres 1(1), 2(1), $3(1), 7(1)$ e 23(1), mostra-se coerente, mas é totalmente inconsistente quando confrontada com caracteres de menor generalidade - 8(1), 9(1), 10(1), 24(1), 26(1), 27(1), 28(1) e 30(1) - que indicam que Trinarea se relaciona com os gêneros de Membracini em vários níveis de universalidade. Assim, aceitar como basal a posição de Trinarea implica em admitir que todos os caracteres presentes nesse gênero, e que são compartilhados com vários gêneros de Membracini, têm surgimentos independentes, o que é insustentável pelo princípio da parcimônia. A hipótese mais confiável deve admitir, para Trinarea, reversão do caráter 21 à condição plesiomórfica, 21R (Fig. 11 d).

Os caracteres 2(1) e 3(1) estão presentes em todos os representantes de Aconophorini, Membracini e Hypsoprorini, exceto Sphongophorus. A ausência destes caracteres, neste gênero, pressupõe que o mesmo tenha uma posição basal e admite a hipótese de táxon merofilético para Hypsoprorini (Fig. 12 a). Esta hipótese não se mantém pelos critérios da parcimônia, pois admite um número maior de passos evolutivos quando confrontada com outras hipótese que contemplam o monofiletismo desse táxon. Isto decorre, basicamente, devido ao número maior de caracteres - 15(1), 32(1) e 33(1) - que sugerem que Sphongophorus compartilha com os demais gêneros de Hypsoprorini, a mesma história evolutiva.

A partir da hipótese favorável ao monofiletismo de Hypsoprorini, é possível elaborar dois cladogramas de mesma topologia e com o mesmo indice de consistência para os caracteres envolvidos - 2(1) e 3(1) - os quais podem admitir surgimentos em níveis de generalidade diferentes. Na figura $12 \mathrm{~b}$, antecipa-se o surgimento dos caracteres 2(1) e 3(1), que são entendidos como sinapomorfias em um nível de generalidade mais abrangente e, desta forma, admite-se a reversão desses caracteres, à condição plesiomórfica, como novidades evolutivas que surgiram no stem-group de Sphongophorus. Na figura 12 c, o surgimento desses caracteres é retardado e admite-se que ocorreram através de processos biológicos independentes, ou seja, os caracteres são entendidos como homoplásticos ao nível sinapomórfico para Aconophorini, Membracini e, inclusive, Trinarea e, ainda, Phylia, Hypsoprora, Notocera e Hypsoprorachis (Hypsoprorini, exceto Sphongophorus). A digressão dos caracteres 2 e 3, decide em favor de considerá-los como sinapomórficos para Aconophorini, Membracini e Hypsoprorini com reversão em Sphongophorus (Fig. 12 b).

O caráter 7(1) pode ser interpretado como homoplástico ao nível sinapomórfico para Hypsoprorini com reversão em Hypsoprorachis e, ainda, ao nível sinapomórfico para Membracini com reversão em Eumusa (Fig. 13 a). Esta interpretação demanda quatro passos evolutivos e tem um índice de consistência baixo. Outra 


\section{HYPSOPRORINI}

\section{HYPSOPRORINI}

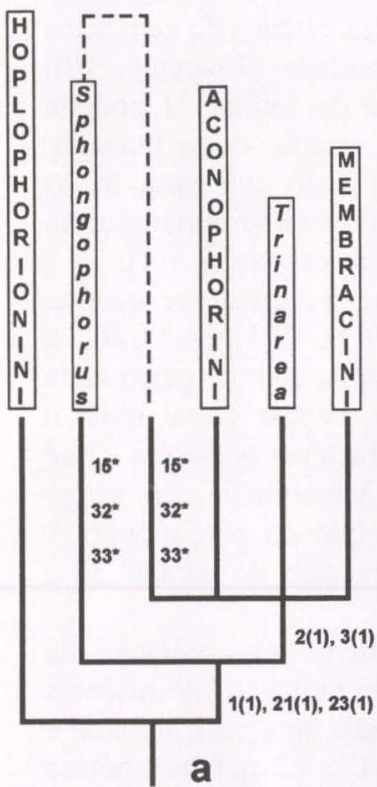

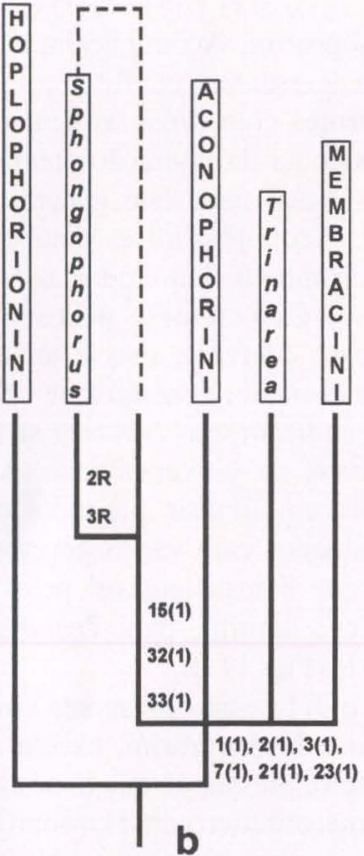

\section{HYPSOPRORINI}

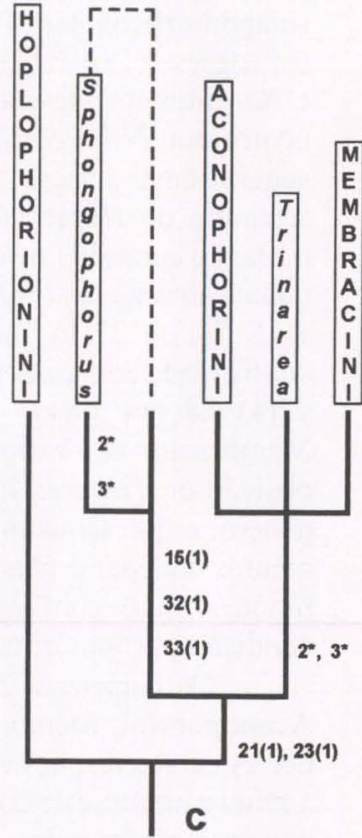

Fig. 12. (a) Hipótese, menos parcimoniosa, que decide contra o monofiletismo de Hypsoprorini; (b, c) Hipóteses, mais parcimoniosas, que decidem em favor do monofiletismo de Hypsoprorini, com diferente niveis de surgimento para os caracteres 2 e 3.

interpretação para o caráter 7(1), que igualmente demandando quatro passos evolutivos, seria admiti-lo como tendo surgido no stem-group de Hypsoprorini, Aconophorini e Membracini, revertendo ao estado plesiomórfico em Hypsoprorachis, Aconophorini e Eunusa (Fig. 13 b). A presença de carena dorso-lateral, estado derivado do caráter 7 , não é propriamente uma condição apomórfica - entende-se como apomorfia a modificação de uma estrutura pré-existente - mas sim a aquisição de uma nova estrutura, uma vez que o estado primitivo do caráter 7 é a ausência da carena dorso-lateral.

AMORIM (1994), ao comentar sobre esses diferentes tipos de apomorfias, destacou que a aquisição de estruturas só pode ocorrer como resultado de mutações precisas, todavia é possível admitir que mutações diferentes podem ter o mesmo produto final, em se tratando de perda. Assim, a probabilidade de aquisição de uma mesma estrutura, independentemente, é menor do que a da perda. Essa digressão para a condição apomórfica do caráter 7 , decide em favor de considerá-lo como tendo um surgimento único, com reversão ao estado plesiomórfico em Hypsoprorachis, Aconophorini e Eunusa.

Os mesmos argumentos utilizados na atribuição do nível de universalidade para o caráter 7, serviram para os caracteres 2(1) e 3(1), muito embora não tratem de aquisição de estrutura, mas de modificação a partir de uma pré-existente. 

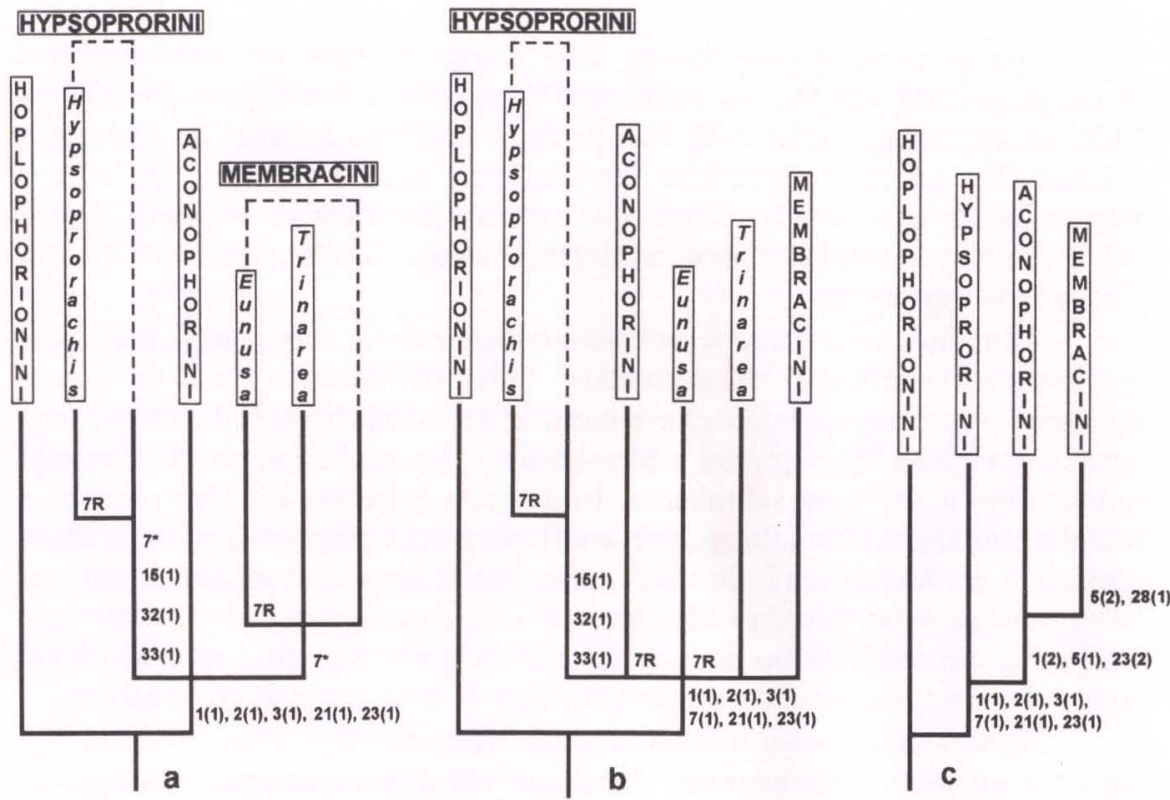

Fig. 13. (a, b) Diferentes niveis de surgimentos para o caráter 7(1) (quatro passos evolutivos); (c) hipótese de relação de parentesco para as tribos de Membracinae.

A hipótese de monofiletismo para Hypsoprorini é ancorada pelo compartilhamento exclusivo da condição apomórfica dos caracteres 15, 32 e 33, já analisados. As relações de parentesco hipotetizadas para os gêneros de Hypsoprorini são confiáveis, pois os caracteres apresentam congruência. Os caracteres 11 e 36 foram interpretados como homoplásticos, (Fig. 10). Se fossem aceitos como sinapomórficos, gerariam uma topologia diferente dentro de Hypsoprorini Esta hipótese, porém, é insustentável pelos critérios da parcimônia, devido o número mais elevado de passos evolutivos que ela admite.

A hipótese de que Aconophorini e Membracini são grupos-irmãos reside no compartilhamento exclusivo dos caracteres 1(2), 5(1) e 23(2), que não apresentam conflitos com outros. Os caracteres 1(2) e 23(2) representam a condição mais apomórfica de séries de transformações lineares e os estados apomórficos intermediários, representam sinapomorfias para Hypsoprorini + Aconophorini + Membracini (Fig. 13 c).

O monofiletismo de Aconophorini foi anteriormente assinalado por DiETRICH \& DEITZ (1991) com base no compartilhamento dos seguintes caracteres: vértice bicolorido, tíbias subfoliáceas e abdome com pelo menos três pares de fenestras dorsais. Esses caracteres foram rejeitados no presente estudo, pois mostraram-se pouco confiáveis.

O vértice bicolorido é um caráter compartilhado apenas por parte das espécies da tribo. A presença de fenestras dorsais no abdome é, em geral, comum em Membracinae e, possivelmente, deve ser informativo num nível de universalidade mais amplo do que aquele em que foi usado. 
Quanto as tíbias subfoliáceas, sabe-se que é exibida por Aconophorini e alguns gêneros de Membracini, sendo que Hypsoprorini e grande parte dos gêneros Membracini, exibem tíbias foliáceas. Então, a partir das relações de parentesco estabelecidas no cladograma para Hypsoprorini, Aconophorini e Membracini, fundamentadas em outros caracteres, que hipóteses poderiam ser levantadas envolvendo as tíbias no estado foliáceo, sem alterar a topologia entre essas três tribos, no cladograma apresentado ?

Admitindo-se que a série de transformação é linear com estados sucessivamente mais apomórficos - tíbias normais _ tíbias subfoliáceas _ tíbias foliáceas duas hipóteses poderiam então ser aventadas: a) a condição foliácea das tíbias é uma sinapomorfia para Hypsoprorini + Membracini + Aconophorini, revertendo nessa última tribo à condição subfoliácea, b) as tíbias foliáceas em Hypsoprorini e Membracini não são homologas, pois em Hypsoprorini surgiram a partir de tíbias normais e em Membracini, de tíbias subfoliáceas, tendo este estado surgido no stem-group de Aconophorini + Membracini. Nota-se que apenas a primeira hipótese contempla o monofiletismo de Aconophorini pela reversão do caráter ao estado apomórfico intermediário, o qual teria ocorrido no stem-group de Aconophorini.

Na segunda hipótese, a condição subfoliáceas das tíbias é uma sinapomorfia para Aconophorini e Membracini. Ocorre que tíbias foliáceas estão presentes em um número elevado de ninfas de Centrotinae e em adultos de Stegaspidinae. Em Hypsoprorini e Membracini estão presentes apenas nos adultos. Assim, para que a série de transformação seja entendida, é necessário que o caráter seja observado em vários outros grupos de Membracidae, considerando qual o seu comportamento em semaforontes adultos e ninfas. A dificuldade de inferir a seqüência correta na série de transformação, assim como os níveis onde os estados de caracteres são informativos, foi decisiva na rejeição deste caráter.

O monofiletismo de Aconophorini está baseada na reversão do caráter 7 à condição plesiomórfica e na reversão do caráter 22 à condição apomórfica intermediária.

A hipótese de monofiletismo que aqui se apresenta para Membracini contrapõe-se à de DIETRICH \& MCKAMEY (1995) que atribui para esse táxon à condição parafilética. O parafiletismo de Membracinae decorreria de Havilandia e Trinarea terem uma relação de parentesco mais próxima com outras tribos de Membracinae do que com qualquer gênero de Membracini. Havilandia foi assinalado como grupo-irmão de Aconophorini, dado o tamanho subigual dos tarsos e Trinarea como grupo-irmão de Hoplophorionini, com base nas tíbias III clavadas e tarsos III reduzidos.

Cabe aqui uma digressão sobre sobre as dificuldades encontradas em acatar aqueles caracteres como definidores das relações de grupo-irmão entre Havilandia e Aconophorini e Trinarea e Membracini.. Faz parte do conhecimento geral de Membracidae, que os tarsos III são sempre mais longos que os tarsos I e II. Então, é possível elaborar pelo menos dois eventos históricos, cujos resultados finais sejam sempre os mesmos, ou seja, o tamanho subigual dos três pares de tarsos, por exemplo: o aumento dos tarsos I e II ou a diminuição dos tarsos III, produzem o mesmo resultado final, muito embora através de processos diferentes. Em Acono- 
phorini os tarsos I e II guardam a mesma proporção em relação às tíbias, se comparado com o que comumente ocorre na família, então o tamanho subigual dos três pares de tarsos deve-se a uma discreta redução dos tarsos III. Contudo, em Havilandia os três pares de tarsos são muito curtos, em relação ao tamanho das tíbias. Assim, é mais provável que o tamanho subigual dos tarsos, neste gênero, seja o resultado final de reduções que ocorreram nos tarsos I e II e de maneira mais acentuada nos tarsos III. Diante destes argumentos decidiu-se, então, não conferir à condição subigual, dos três pares de tarsos, um poder de decisão tão grande ao ponto de nela ancorar uma hipótese de ancestralidade comum para Aconophorini e Havilandia.

Quanto as tíbias III de Trinarea e Hoplophorionini, ambas são reconhecidas pelo vocábulo "clavada", pois lembram a forma de uma clava. Porém, entende-se aqui que os processos biológicos que as levaram a apresentar essa forma, se deram por eventos históricos completamente independentes. Nos comentários sobre o caráter 20 apresentam-se as explicações devidas que sustentam a hipótese de que, embora designadas clavadas, as tíbias desses táxons não guardam homologia entre si.

O monofiletismo de Membracinae está assinalado pela carena mediana percurrente laminada e pelo padrão de venação das asas anteriores onde Sa é indivisa e os ramos $\mathrm{S}_{1}$ e $\mathrm{S}_{2}$ estão fundidos.

Dentro de Membracini o grupo um (GI), composto por Lewdeitzia, Leioscyta e Havilandia, é suportado por uma única sinapomorfia, caráter 29(1), e não foi possível esclarecer a relação entre esses gêneros. Havilandia compartilha com Eunusa à condição apomórfica do caráter 4 e com Enchenopa, Campylenchia, Kronides, Membracis, Enchophyllum, Phyllotropis e Folicarina, à condição apomórfica do caráter 34. As possibilidades de reunir Havilandia com esse grupo de gêneros ou com Eunusa demandam um número de passos evolutivos maior do que aquele que o reúne com Leioscyta e Lewdeitzia.

O segundo grupo de gêneros (GII) é ancorado pelo compartilhamento exclusivo da condição apomórfica dos caracteres 26 e 30 . Acredita-se que as relações de parentesco para os cinco gêneros que compõem esse grupo, estejam resolvidas.

O gênero Eunusa apresenta reversão à condição plesiomórfica para os caracteres 5 e 7 . Se a condição plesiomórfica destes caracteres forem entendidas como ausência, e não como reversão, a posição de Eunusa passa a ser a de grupo-irmão de Aconophorini + Membracini ou de grupo-irmão de Membracini, dependendo da ponderação maior ou menor que seja atribuída ao caráter 5 ou ao 7 . Contudo, se a condição plesiomórfica for entendida como reversão, Eunusa surge, naturalmente, como táxon basal do grupo dois (GII).

As divergências de topologia que ocorrem entre os seis cladogramas gerados pelo comando ie*; residem unicamente na posição de Eumusa e na relação de parentesco entre os grupos de gêneros de Membracini (GI, GII e GIII). Dentre os seis cladogramas gerados pelo comando ie*;, três conjuntos com dois cladogramas cada, podem ser identificados: o primeiro conjunto admite Eunusa como grupo-irmão de Aconophorini + Membracini, o segundo como grupo-irmão de Membracini 
e no terceiro Eunusa é incluído em Membracini como táxon mais basal de GII. As divergências entre os dois cladogramas de cada conjunto decorrem da relação de parentesco estabelecidas para GI, GII e GIII. Essas divergências são: a) as relações não resolvidas entre GI, GII e GIII, são expressas por uma tricotomia. b) GI + GIII é grupo irmão de GII.

Aplicando-se o comando xs w; que adiciona, a posteriori, pesos sucessivos aos caracteres considerados mais confiáveis (Tab. II), dois cladogramas foram gerados. Esses cladogramas que resultaram da aplicação repetida do comando ie*; incluem Eunusa como gênero mais basal de GII. Sobre esses dois cladogramas aplicou-se o comando ne; cujo cladograma de consenso está expresso na figura 10.

O terceiro grupo de gêneros de Membracini (GIII) é reunido com base no compartilhamento da condição apomórfica do caráter 31 , mas as relações entre os gêneros aí acomodados estão, penas, parcialmente esclarecidas. Tritropidia é o gênero mais basal deste agrupamento. No nível de universalidade seguinte ocorre uma politomia formada por Enchenopa, Campylenchia, Kronides e a raiz do agrupamento que reúne Membracis, Enchophyllum, Phyllotropis e Folicarina.

DIETRICH \& MCKAMEY (1995) comentam que Campylenchia Stål, 1869 e Enchenopa Amyot \& Serville, 1843 são completamente idênticos. Realmente a separação das espécies se faz por uma sutileza da carena dorso-transversal, sobra a qual Stål afirma, na diagnose de Campylenchia, ser ligeiramente mais aproximada da margem superior do processo anterior, se comparada com Enchenopa, cuja carena divide o processo anterior ao meio. Como o limite entre os gêneros é feito por um mero detalhe, a decisão de acomodar as espécies em um dos gêneros acaba sendo arbitrária. As observações efetuadas ao âmbito desse trabalho indicam que os gêneros podem ser sinônimos.

DIETRICH \& MCKAMEY (1995) referem-se ao agrupamento formado por Membracis, Phyllotropis, Folicarina e Enchophyllum como um complexo de gêneros problemático, pois são distinguidos apenas pela combinação de quatro caracteres, cada um com dois estados. Para este caso em particular é necessário estabelecer os limites de cada um dos gêneros para que as relações entre eles sejam determinadas.

\section{CONCLUSÕES}

As relações de parentesco hipotetizadas para as tribos de Membracinae apontam para uma filogenia assimétrica (pente hennigiano) e indicam, no cladograma, em seqüênciação, Hoplophorionini [ Hypsoprorini [ Aconophorini [ Membracini ] ] ].

O monofiletismo de Hoplophorionini é altamente confiável, estando ancorado por cinco sinapomorfias: carena mesepisternal presente e bem desenvolvida, projetando-se para o mesepimero; sutura metanotal mediana ausente; triângulo mesocoxal presente; tíbias III com as arestas I e II fundidas nos três quartos apicais e tarsos III menores que os tarsos I e II.

A hipótese de monofiletismo para Hypsoprorini está baseada no compartilhamento exclusivo dos seguintes caracteres: margem lateral do processo posterior 
sobrepondo a margem interna das tégminas; frênulo situado no meio da asa posterior ou um pouco antes e asas posteriores com margem anterior sinuosa na região do limbo.

O monofiletismo de Aconophorini é a hipótese considerada mais frágil do cladograma. Ela está baseada na reversão do caráter 7 à condição plesiomórfica presença de carena dorso-lateral - e na reversão do caráter 22 à condição apomórfica intermediária, ou seja, tíbias III com cerdas cuculadas da aresta III, menos proeminentes que as das arestas I e II.

A hipótese de que Aconophorini e Membracini são grupos-irmãos reside no compartilhamento exclusivo dos seguintes caracteres: superfície do corpo recoberta de cera apenas na fase ninfa, caráter 1(2); carena mediana percurrente laminada anteriormente, caráter 5(1) e tíbias III com espinhos bem desenvolvidos nas arestas I e II, caráter 23(2). A condição apomórfica intermediária para os caracteres 1 e 23 representam sinapomorfias para Hypsoprorini + Aconophorini + Membracini.

O monofiletismo de Membracinae está assinalado pela carena mediana percurrente laminada e pelo padrão de venação das asas anteriores onde Sa é indivisa e os ramos $S_{1}$ e $S_{2}$ estão fundidos.

Dentro de Membracini as relações entre gêneros reunidos em GI e GIII não ficaram esclarecidas e portanto demandam estudos mais profundos, sobretudo no levantamento de caracteres. Particularmente, no G III é necessário um trabalho para que os gêneros ali reunidos sejam melhor delimitados com base em caracteres diagnósticos mais precisos.

As divergências de topologia que ocorrem entre os seis cladogramas gerados pelo comando ie*; residem unicamente na posição de Eunusa e na relação de parentesco entre os três grupos de gêneros de Membracini (GI, GII e GIII). Os outros comandos utilizados para a obtenção do cladograma final foram xs w; e ne;.

\section{REFERÊNCIAS BIBLIOGRÁFICAS}

Amorim, D. DE Souza. 1994. Elementos Básicos de Sistemática Filogenética.

São Paulo, Sociedade Brasileira de Entomologia, 314p.

DeITZ, L.L. 1975. Classification of the higher categories of the New World treehoppers (Homoptera: Membracidae). North Carolina Agric. Exp. Stat. Tech. Bull. 225: 1-177.

Dietrich, C.H. \& L.L. Deitz. 1991. Numerical Phenetic and Cladistic Analysis of Treehoppers. Tribe Aconophorini (Homoptera: Membracidae: Membracinae).

Ann. Entomol. Soc. Amer. 84 (3): 228-238.

DIETRICH, C.H. \& S.H. MCKAMEY. 1995. Two new Neotropical treehopper genera and investigation of the phylogeny of the subfamily Membracinae (Homoptera: Membracidae). Proc. Entomol. Soc. Washington 97 (1):1-16.

FARRIS, J.S. 1988. Hennig 86 reference, version 1.5. Computer program and documentation, publicado pelo autor, sem paginação.

Funkhouser, W.D. 1913. Homologies of the wings of the Membracidae. Ann.

Entomol. Soc. Amer. 6: 74-97.

McKameY, S.H. \& L.L. Deitz. 1996. Generic revicion of the New World tribe 
Hoplophorionini (Hemiptera: Membracidae: Membracinae). Syst. Entomol. 21: $295-342$.

WATRous, L.E. \& Q.D. WhEelER. 1981. The out-group comparison method of character analysis. Syst. Zool. 30 (1): 1-11.

Recebido em 01.VIII.1997; aceito em 01.X.1998. 